\title{
Hemozoin impairs cell cycle progression and promotes chemokine release in human microvascular endothelial cells
}

\author{
Nicoletta Basilico ${ }^{1 *}$, Daniela Girelli', Sarah D’Alessandro ${ }^{2}$, Yolanda Corbett ${ }^{2}$, Mauro Prato ${ }^{3}$, Silvia Carluccio , \\ Serena Del Bue ${ }^{1}$, Pasquale Ferrante ${ }^{1}$, Donatella Taramelli ${ }^{2}$ \\ From Challenges in malaria research \\ Basel, Switzerland. 10-12 October 2012
}

\section{Background}

Cerebral malaria $(\mathrm{CM})$ is a fatal complication of P. falciparum infection caused by the cytoadherence of infected erythrocytes to brain endothelial cells followed by microcirculatory obstruction, blood-brain barrier (BBB) damage, ring hemorrhages, inflammatory response and neurological sequelae. The combination of both parasite and host factors are involved in the pathogenesis of CM. In particular, malarial pigment, hemozoin ( $\mathrm{HZ}$ ) was shown to interfere with monocytes and endothelial cell functions. Recently our group demonstrated that $\mathrm{HZ}$ enhanced total gelatinolytic activity in endothelial cells by inducing ex novo matrix metalloproteinases-9 (MMP9) and promoting proMMP-9 protein expression (Prato et al., 2011).

\section{Materials and methods}

In the present work human dermal microvascular endothelial cells (HMEC-1) were treated with native HZ isolated from P.flaciparum cultures. Cell morphology was evaluated by optical microscopy, chemokine (CXCL-8, CCL-5) production by ELISA, proliferation/viability by MTT assay and trypan blue count, apoptosis and cell cycle by FACS analysis, using Annexin V $l$ Propidium Iodide (PI) and only PI, respectively.

\section{Results}

Modifications of cell morphology were observed in HZtreated cells, which showed elongated form instead of the classical polygonal shape. Moreover, $\mathrm{HZ}$ stimulated the production of the chemokines CXCL-8 and CCL-5,

${ }^{1}$ Dipartimento di Scienze Biomediche, Chirurgiche e Odontoiatriche,

Università di Milano, Milan, Italy

Full list of author information is available at the end of the article involved in neutrophils/monocytes recruitment, in a dose and time-dependent manner. After 48-72 hours of culture in the presence of $\mathrm{HZ}$, a reduction of cells number/proliferation, compared to the control, was observed. However, FACS analysis indicated that $\mathrm{HZ}$ treatment did not induce apoptosis of endothelial cells. On the contrary, $\mathrm{HZ}$ increased the percentage of GO/G1-phase cells and decreased S-phase cells, indicating a reduction of the growth fraction cells.

\section{Conclusions}

The present data suggest that $\mathrm{HZ}$ promotes chemokines release and inhibits endothelial cells growth. As a consequence, neutrophils/monocytes recruitment is favoured resulting in the amplification of the inflammatory response. Moreover, in case of vascular injury, the damaged monolayer could not be regenerated by proliferating endothelial cells. All these events may concur to impair BBB functions in CM.

\section{Author details}

'Dipartimento di Scienze Biomediche, Chirurgiche e Odontoiatriche, Università di Milano, Milan, Italy. ${ }^{2}$ Dipartimento di Scienze Farmacologiche e Biomolecolari, Universitá di Milano, Milan, Italy. ${ }^{3}$ Dipartimento di Neuroscienze e Dipartimento di Genetica, Biologia e Biochimica, Universitá di Torino, Turin, Italy.

Published: 15 October 2012

doi:10.1186/1475-2875-11-S1-P9

Cite this article as: Basilico et al:: Hemozoin impairs cell cycle progression and promotes chemokine release in human microvascular endothelial cells. Malaria Journal 2012 11(Suppl 1):P9.
C 2012 Basilico et al; licensee BioMed Central Ltd. This is an Open Access article distributed under the terms of the Creative Commons Attribution License (http://creativecommons.org/licenses/by/2.0), which permits unrestricted use, distribution, and reproduction in any medium, provided the original work is properly cited. 